\title{
Heat Index Based Medical Alert System for Geriatrics
}

\author{
R.Priyakanth $^{\# 1}$, Daggula Bhavitha ${ }^{* 2}$, Mahesh Babu Katta ${ }^{\# 3}$, N.M.Sai Krishna ${ }^{* 4}$ \\ \#,* Department of Electronics and Communication, BVRIT Hyderabad College of Engineering for Women, \\ Hyderabad, Telangana, India \\ ${ }^{1}$ priyakanthr@gmail.com \\ ²havithadaggula@gmail.com \\ ${ }^{3}$ mahes.katta@gmail.com \\ ${ }^{4}$ saikrishna.nyshadam@gmail.com
}

\begin{abstract}
Human body has a natural tendency to adjust itself to the internal temperature of the body irrespective of the changes in the external condition in order to maintain good health.But this is not the case with elder citizens. They are more prone to heat stress. Most of them have continual medical condition that changes normal body responses to heat. The intake of prescription medicines also impair the body's ability to adjust to its normal temperature. Hence Geriatrics, receiving special health care need assistive tools for knowing temperature and humidity outside the house before stepping out. These tools also help in taking precautions for healthy living. Heat index is one such parameter which gives a measure of how hot it really feels when relative humidity is factored with the actual air temperature and hence can be used to alert the geriatrics or their custodians to minimize the risk of exposure to heat stress.

This work presents the design of heat index based medical alert system using Arduino, Temperature and humidity sensor. An android app is developed to display the temperature and humidity values sensed by the sensor periodically and alerts the needy based on the heat index measured. This android app is also helpful for visually impaired by reading out loud the sensor values and giving caution.
\end{abstract}

Keyword-Geriatrics;Heat Index; Arduino; DHT11; Android; MIT App Inventor

\section{INTRODUCTION}

Human beings are mammals called Homotherms [1] and they try to regulate their body temperature close to about $98.4^{\circ} \mathrm{F}$. If it deviates for more than a few degrees from $98.4^{\circ} \mathrm{F}$ then it could create serious consequences and threat to life. The temperature of the human body generally is influenced by the temperature of fluids, solids or the surroundings which includes the atmospheric air.

In the light of the evidence of adaptation to normal temperatures it is seen that a higher number of deaths occur at unusually extreme temperatures. A long-term exposure shows higher mortality during summer or winter time temperature variability which increases with climate change.

An investigation by Zanobetti et al [2] shows that a long-term increase in summer temperature variability may increase the risk of mortality in different subgroups of susceptible older populations [3]. Various studies of short-term mortality displacement reveal that a higher number of deaths are associated with heat and heat waves. There are merely deaths advanced by a few weeks [4] [5], although heat may reduce life expectancy in a more substantial way, for example, among children in Delhi, India [4]. However, these studies indicate that the variability of summer time temperature is the major factor among cities revealing the effects of very hot days [5], [6].

The centres for disease control and prevention provide a list of warning signs and symptoms of heat illness [11].Some of these symptoms are listed below.

1. Heat Cramps with symptoms, painful muscle cramps and spasms usually in legs and abdomen and heavy sweating is the first sign of heat related illness, and may lead to heat exhaustion or stroke.

2. Heat exhaustion with some symptoms is heavy sweating, weakness; cool, pale, clammy skin; fast, weak pulse; possible muscle cramps, dizziness, nausea, vomiting or fainting.

3. Heat stroke symptoms are altered mental state, throbbing headache, confusion, nausea, dizziness, shallow breathing, body temperature above $103^{\circ} \mathrm{F}$; hot, red, dry or moist skin; rapid and strong pulse; faints or lose consciousness.

To minimize these symptoms of heat illness and to take necessary precautions, we recommend a method of alerting the Geriatrics based on heat index calculated. This automatic alerting system is designed on Arduino platform.

Arduino is an open-source electronics platform. It is an easy-to- use hardware and software. Arduino is intended for making any interactive projects. It senses by receiving inputs from many sensors, and affects its 
surroundings by controlling lights, motors etc. Arduino performs the operations specified in the form of code in a loop until its power supply is switched off.

\section{Design Block Structure And Schematic}

The complete design process is presented in Fig. 1 in the form of a block structure. The functioning starts with the Digital Humidity and Temperature sensor (DHT) giving the values of ambient temperature $\left({ }^{\circ} \mathrm{F}\right)$ and relative humidity (\%) once powered from Arduino. From the measured parameters heat index is calculated. These values along with the alert are transmitted using Bluetooth wirelessly and are viewed in the android application designed using MIT App Inventor. Additional feature provided in the app is that the sensed values can be read out loud so that this electronic aid will be helpful for visually impaired.

This designed device is placed outside the house and the received values refer to the conditions outside. Based on the alert received, the user takes necessary precautions. The Schematic design is displayed in Fig. 2.

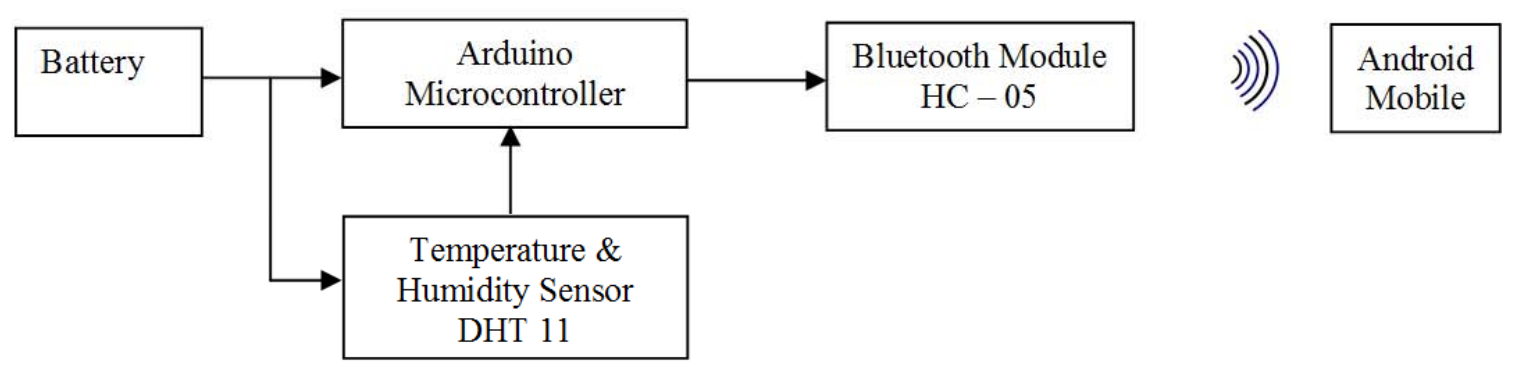

Fig.1.Block Structure Design

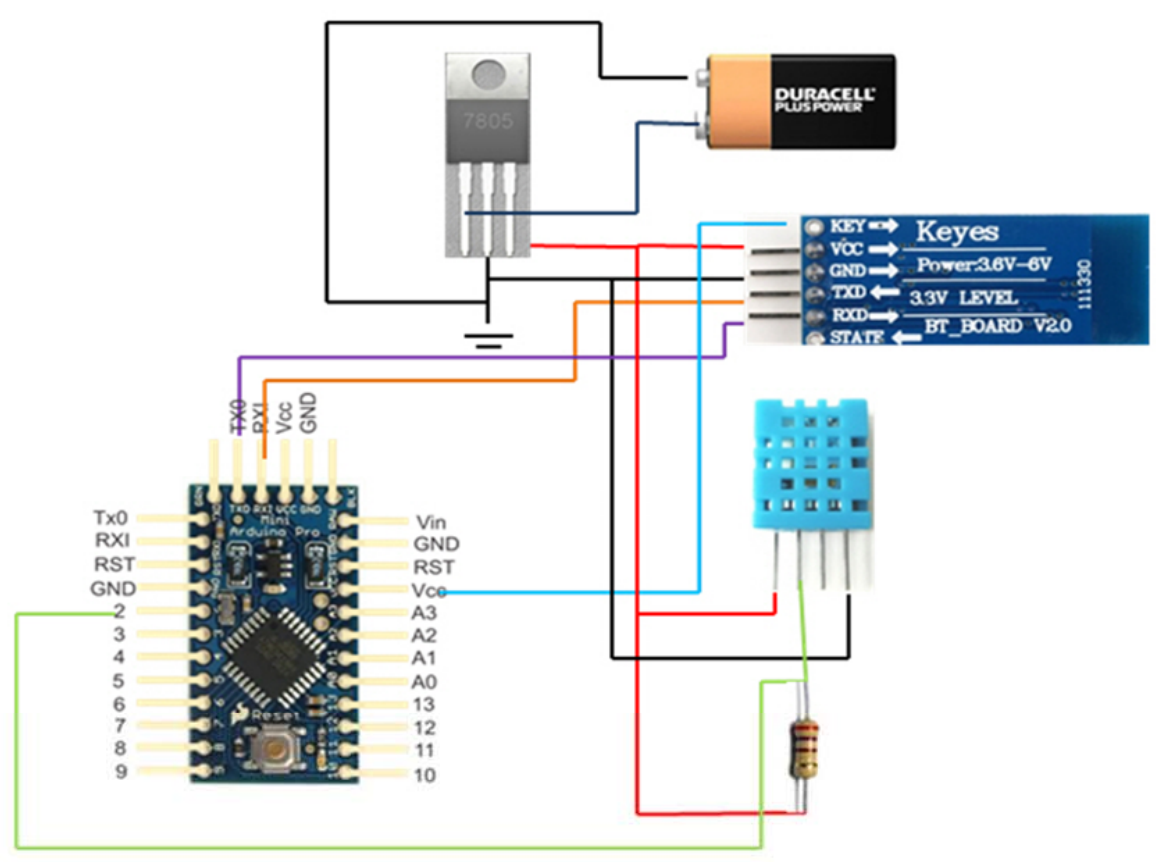

Fig.2. Schematic Diagram

\section{LIST OF COMPONENTS USED}

\section{A. Arduino Pro Mini}

The Arduino Pro Mini shown in Fig. 3 is an ATmega328 based microcontroller board with a built-in Arduino boot loader. It consists of 14 digital input/output pins among which 6pins are PWM outputs, 8 analog inputs, an on-board resonator, a reset button, and holes for mounting the pin headers. The board can run on USB power when connected to PC using the USB port. Pro Mini has two versions, one runs at $3.3 \mathrm{~V}, 8 \mathrm{MHz}$ and the other at $5 \mathrm{~V}, 16 \mathrm{MHz}$. 


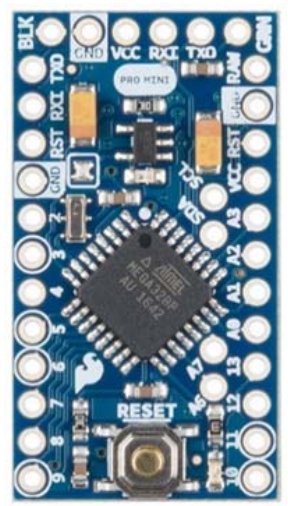

Fig. 3. Arduino Pro Mini board and its pin structure[12]

\section{B. Bluetooth Module(HCO5)}

HC-05 Bluetooth Module is an easy to use Bluetooth SPP (Serial Port Protocol) module presented in Fig.4. It works on $\mathrm{DC} 5 \mathrm{~V}$ and is designed for transparent wireless serial connection setup. Its serial communication is an easy way to interface with controller or PC. A switching between master \& slave modes is provided by Bluetooth module.

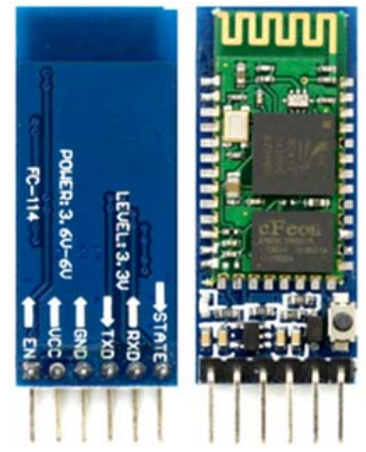

Fig. 4. HC-05 Bluetooth Module[16]

TABLE I

Pin Description - HC 05

\begin{tabular}{|c|c|c|}
\hline Pin & Description & Function \\
\hline VCC & $+5 \mathrm{~V}$ & Connect to $+5 \mathrm{~V}$ \\
\hline GND & Ground & Connect to Ground \\
\hline TXD & $\begin{array}{l}\text { UART_TXD, } \\
\text { Bluetooth serial } \\
\text { sending PIN }\end{array}$ & Connect with the MCU's (Microcontroller and etc) \\
\hline RXD & $\begin{array}{c}\text { UART_RXD, } \\
\text { Bluetooth serial } \\
\text { sending receiving } \\
\text { PIN }\end{array}$ & $\begin{array}{l}\text { Connect with the MCU's (Microcontroller and etc) } \\
\text { TXD PIN. }\end{array}$ \\
\hline KEY & Mode switch input & $\begin{array}{l}\text { If it is input low level or connect to the air, the } \\
\text { module is at paired or communication mode. If it's } \\
\text { input high level, the module will enter to AT mode }\end{array}$ \\
\hline
\end{tabular}




\section{DHT11}

DHT11 is a temperature \& humidity sensor which gives a calibrated digital signal output. Excellent long term stability \& high reliability are achieved by using the digital signal acquisition technique \& temperaturehumidity sensing technology. This sensor includes a resistive-type humidity measurement component based on negative temperature coefficient (NTC). It offers excellent quality \& fast response and can be connected to a high performance 8-bit microcontroller. DHT11 offers anti interference ability which is cost effective. Basic specifications of DHT11 are shown in Table II.

Accurate humidity calibration is done for DHT11. One time programmable (OTP) memory is available for storing calibration coefficients. Its pin structure is shown in Fig. 5. It is the best choice for various applications due to its small size and low power consumption. It can be used by the most demanding and challenging applications also. DHT11 is 4-pin single row pin package.

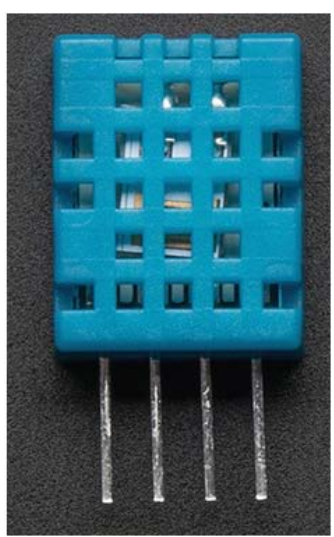

Pin 1: Vec Pin 2: Data Pin 3: NC Pin 4: GND (from left to right)

Fig. 5.DHT11 Sensor and pin nomenclature[15]

TABLE II

Basic Specifications of DHT 11

\begin{tabular}{|c|c|}
\hline Temperature Range & $0^{\circ}$ to $50^{\circ} \mathrm{C}$ \\
\hline Relative Humidity & 20 to $90 \%$ \\
\hline Temperature Accuracy & $\pm 2^{\circ} \mathrm{C}$ \\
\hline Relative Humidity Accuracy & $\pm 5 \%$ \\
\hline
\end{tabular}

\section{Breakout Module}

FTDI (Future Technology Devices International) FT232RL is a basic breakout board for USB to serial conversion. This board with the FTDI cable can be used to work with official Arduino and any cloned 3.3V Arduino boards. It can also be used for any general serial applications. When a new sketch is downloaded using Arduino IDE, Auto reset of Arduino target is allowed by DTR pin.

USB protocol stack is implemented by FTDI chips. Using this protocol, computer can load the right driver for this hardware. Managing Data transactions with PC is also done very easily. This breakout module displayed in Fig. 6 is used to transfer the program onto the memory of Arduino board. 

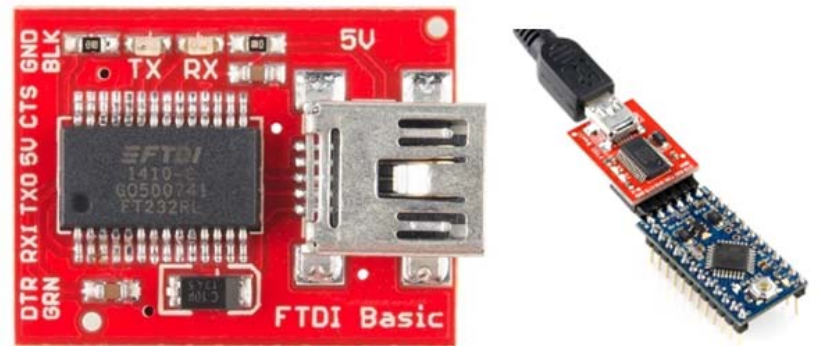

Fig. 6. Breakout Module[13] and Connection with Arduino Pro mini for code dumping[14]

\section{PARAMETERS SENSED AND CALCULATED}

\section{A. Temperature}

The quantity which determines the direction of the flow of heat between the two bodies kept in contact is called temperature. It is also measured as the degree of hotness or coldness of a body or environment. It is a measure of the average kinetic energy of the particles in a sample of matter, expressed in terms of units or degrees designated on a standard scale. The degree of heat in the body of a human being is usually about $37.0^{\circ} \mathrm{C}$ $\left(98.6^{\circ} \mathrm{F}\right)$.

\section{B. Relative Humidity}

Relative humidity $(\mathrm{RH})$ is the ratio of the actual partial vapour pressure of water to the saturation vapour pressure at that temperature. The saturation vapour pressure of water increases rapidly with temperature, from 610 Pascal at zero degrees to $2800 \mathrm{~Pa}$ at $23 \mathrm{oC}$. At $100 \mathrm{oC}$ the vapour pressure reaches $101,000 \mathrm{~Pa}$, which is about atmospheric pressure.

\section{Heat Index}

Heat index also known as the apparent temperature, is what the temperature feels like to the human body when relative humidity is combined with the air temperature [7]. There is direct relationship between the air temperature and relative humidity and the heat index. As the air temperature and relative humidity increases/decreases, the heat index increases / decreases.

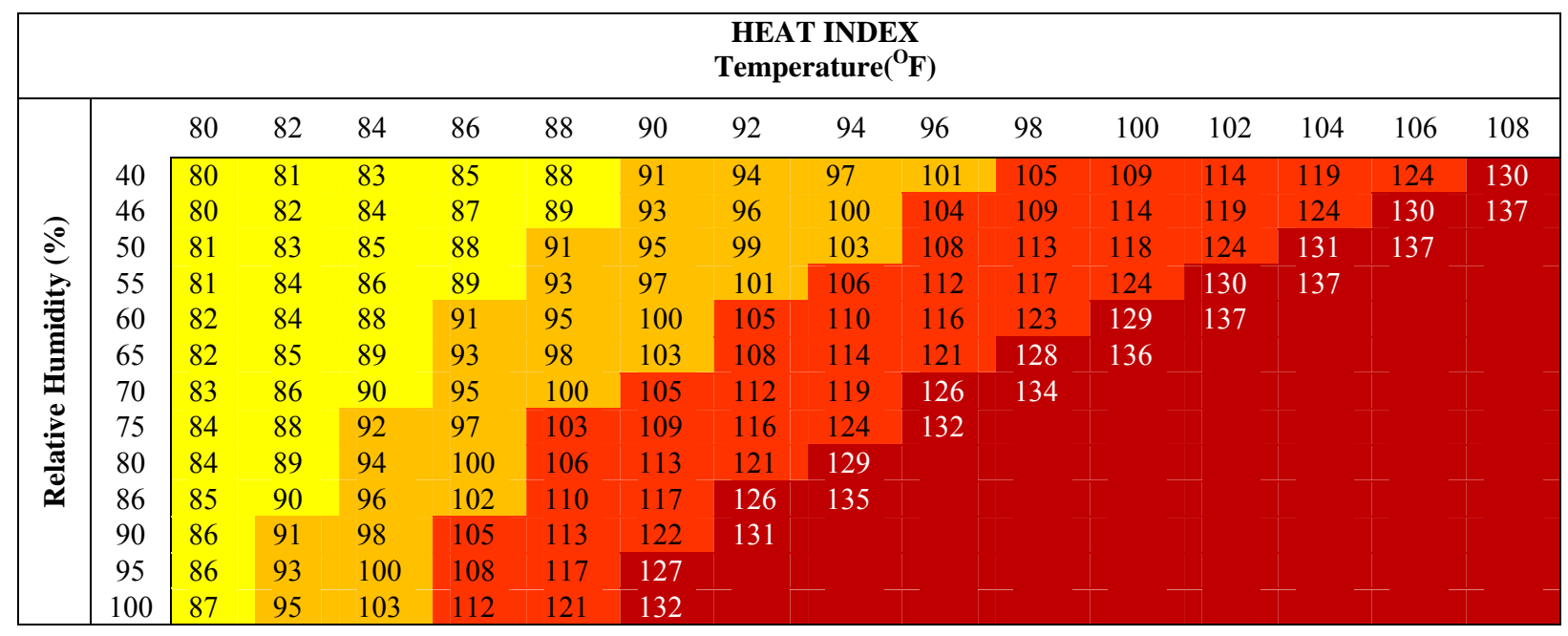

Caution

To determine the heat index using the chart given by National Oceanic and Atmospheric Administration (NOAA) shown in Fig. 7, we need to know the air temperature and relative humidity. 
TABLE III

Heat Index [7]

\begin{tabular}{|c|c|l|}
\hline Classification & Heat Index & \multicolumn{1}{|c|}{ Effect on the body } \\
\hline Caution & $80^{\circ} \mathrm{F}-90^{\circ} \mathrm{F}$ & $\begin{array}{l}\text { Fatigue possible with prolonged exposure and/or physical } \\
\text { activity }\end{array}$ \\
\hline Extreme caution & $90^{\circ} \mathrm{F}-103^{\circ} \mathrm{F}$ & $\begin{array}{l}\text { Heat stroke, heat cramps, or heat exhaustion possible with } \\
\text { prolonged exposure and/or physical activity }\end{array}$ \\
\hline Danger & $103^{\circ} \mathrm{F}-124^{\circ} \mathrm{F}$ & $\begin{array}{l}\text { Heat cramps or heat exhaustion likely, and heat stroke } \\
\text { possible with prolonged exposure and/or physical activity }\end{array}$ \\
\hline Extreme Danger & $\begin{array}{c}125^{\circ} \mathrm{F} \text { or } \\
\text { higher }\end{array}$ & Heat stroke highly likely \\
\hline
\end{tabular}

Heat Index is calculated from the measured parameters Temperature $\left({ }^{\circ} \mathrm{F}\right)$ and Relative Humidity $(\%)$ [9].

$$
\begin{aligned}
\text { Heat Index }=- & 42.379+2.04901523 T+10.14333127 R-0.22475541 T R-6.83783 \times 10^{-3} T^{2} \\
& -5.481717 \times 10^{-2} R^{2}+1.22874 \times 10^{-3} T^{2} R+8.5282 \times 10^{-4} T R^{2}-1.99 \times 10^{-6} T^{2} R^{2}
\end{aligned}
$$

where $\mathrm{R}$ is Relative humidity $(\%)$ and $\mathrm{T}$ is Air Temperature $\left({ }^{\circ} \mathrm{F}\right)$

If geriatrics are exposed to direct sunlight, the heat index [10] value can be increased upto $15^{\circ} \mathrm{F}$. As shown in Table III. Heat indices meeting or exceeding $103^{\circ} \mathrm{F}$ can lead to dangerous heat disorders with prolonged exposure and/or physical activity in the heat.

\section{COMMUNICATION PROCESS}

Synchronization and communication between DHT11 sensor and Micro Computer Unit (MCU) is done using a single-bus data format $4 \mathrm{~ms}$ is the time elapsed for and one communication process. Data consists of decimal and integral parts. 40-bit data is transmitted and the higher data bit is sent first by the sensor.

\section{A. Overall Communication Process}

DHT11 stays in low power consumption mode by default. When there is no signal from Arduino (MCU) sends a start signal and completes sending it. Then DHT11 sends 40-bit data as response signal which include temperature \& relative humidity information to MCU. DHT11 gives the response only when the MCU sends the start signal. DHT11 again shifts into low power consumption mode until MCU sends start signal again. This process is shown in the form of a timing diagram in Fig.8.

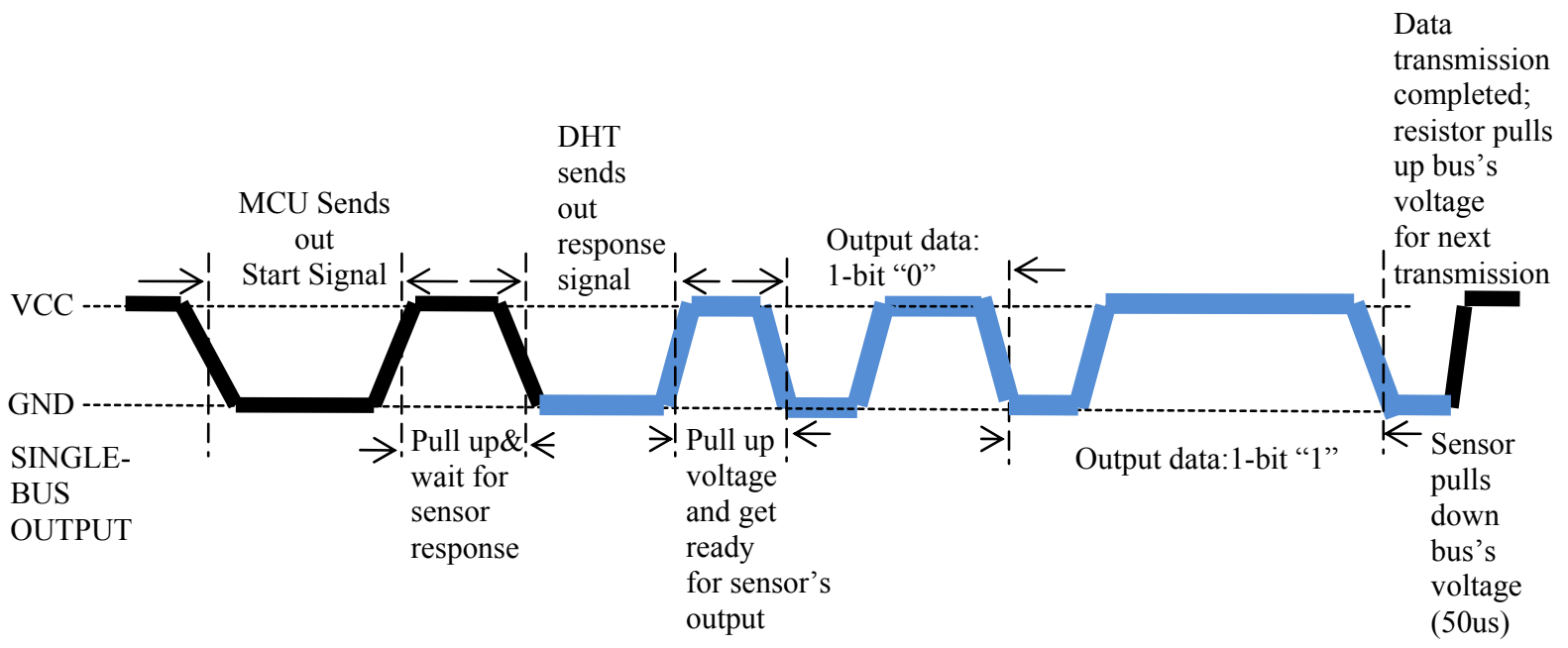

MCU signalDHT signal

Fig. 8. Overall Communication Process 


\section{B. MCU sends out Start signal to DHT}

The data single-bus free status is at high voltage level as shown in the timing diagram in Fig.9. The program of MCU will set Data Single-bus voltage level from high to low when the communication between MCU and DHT11 begins. It takes at least $18 \mathrm{~ms}$ for DHT11 to detect MCU's signal. Then MCU will pull up voltage and wait $20-40 \mu$ s for DHT's response.

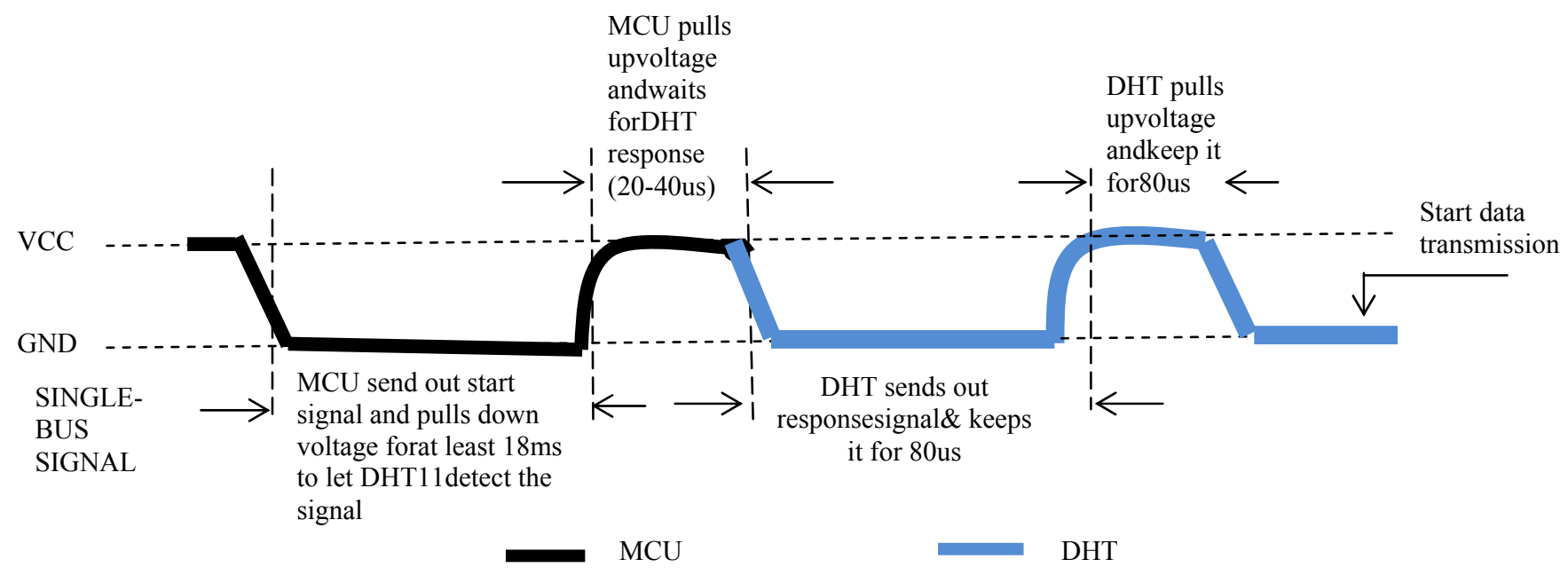

\section{DHT Responses to $M C U$}

Fig. 9.MCU sends out start signal and DHT responses

The DHT detects the start signal from MCU and sends out a low voltage level response signal which lasts for $80 \mu \mathrm{s}$. For sending data the program of DHT sets data signal-bus from low to high voltage level which is kept for $80 \mu \mathrm{s}$. During this time DHT prepares for sending data. Data ' 0 ' and ' 1 ' indication is shown in Fig.10 \& Fig.11.

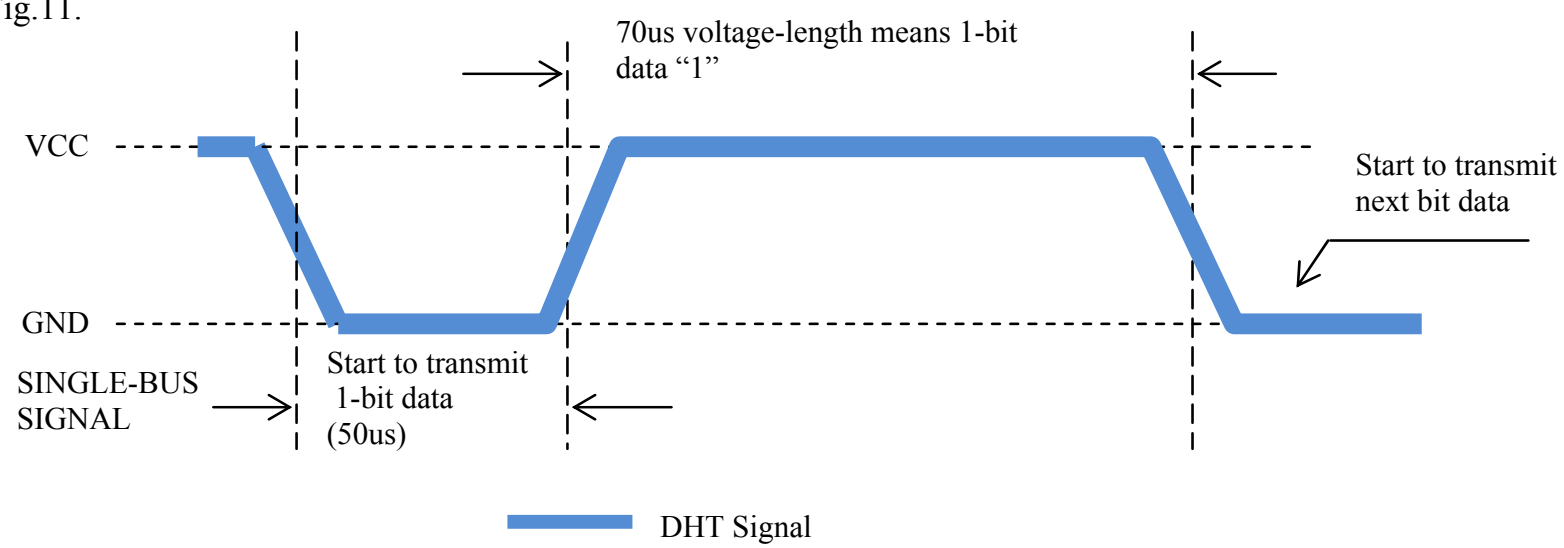

Fig. 10.Data '0'indication

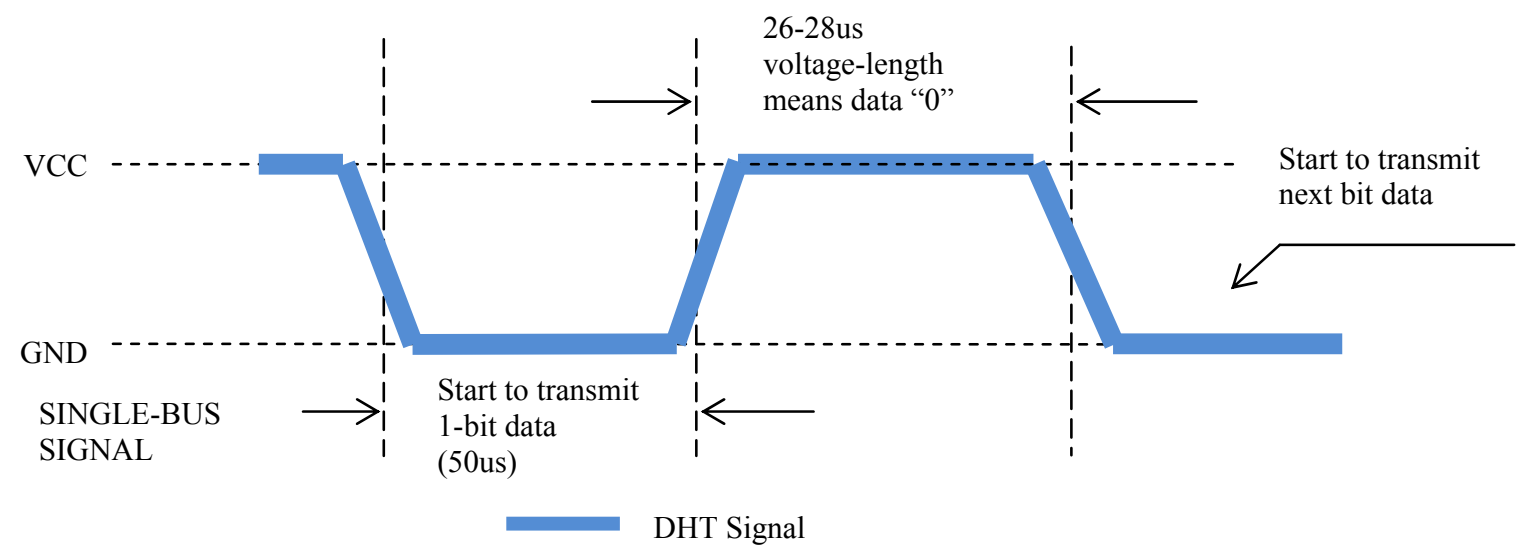

Fig. 11.Data ' 1 ' indication 
The temperature and humidity sensor, DHT11 values i.e., temperature and humidity, are communicated to the android mobile through Bluetooth into an Android application developed using MIT App Inventor.

\section{VI.RESULts}

First the results are observed in Arduino IDE Serial Monitor in Fig.12. Then results are communicated serially using Bluetooth (HC-05) and observed in Bluetooth Terminal application shown in Fig.13, which is installed from Google play store before designing the android app in MIT APP INVENTOR.

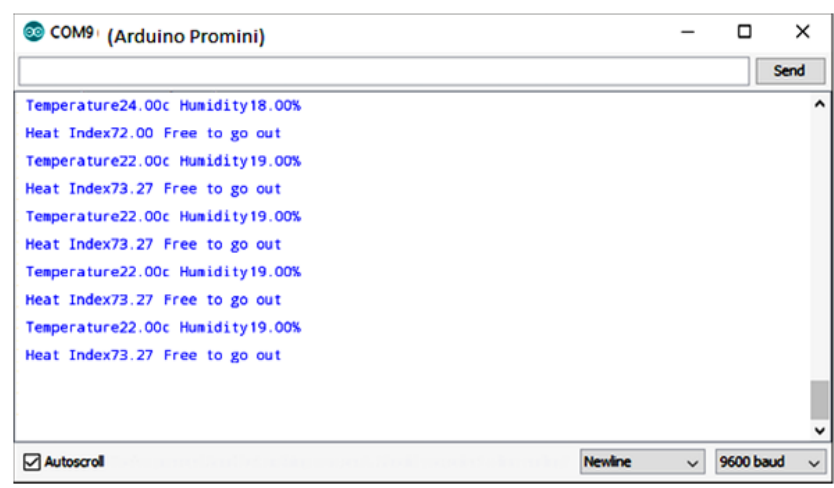

Fig.12. Sensed Data display in Arduino IDE Serial Monitor

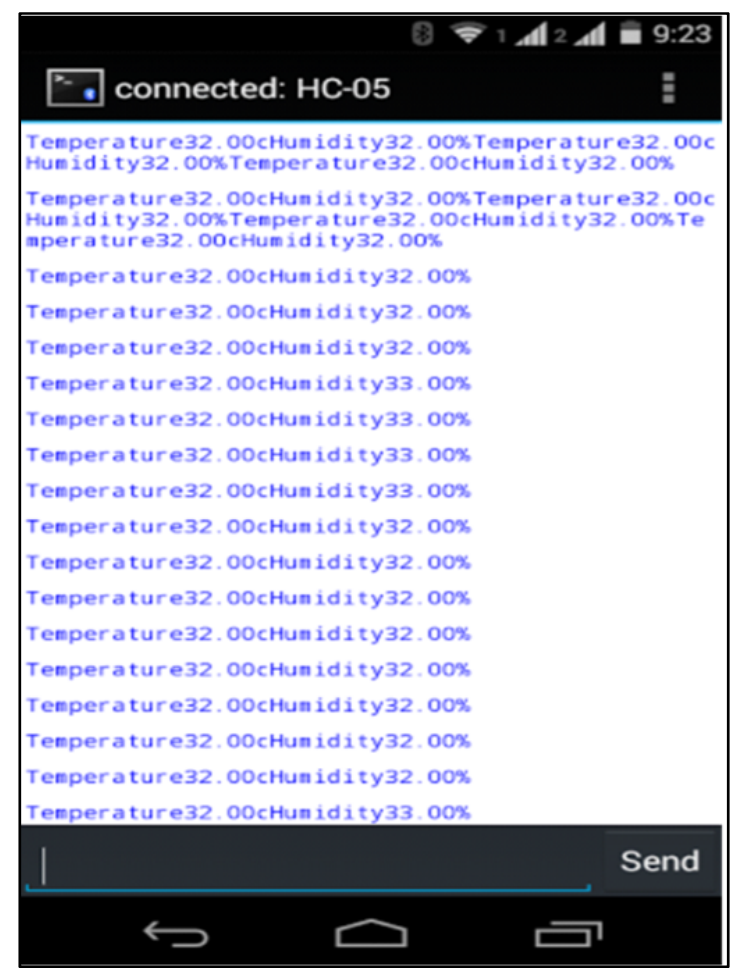

Fig.13. Sensed Data Display in Bluetooth Terminal APP in Android Mobile

\section{DESIGNING ANDROID APPLICATION - MIT APP INVENTOR}

MIT App Inventor is an innovative beginner's introduction to programming and app creation that transforms the complex language of text-based coding into visual, drag-and-drop building blocks. The simple graphical interface grants even an inexperienced novice the ability to create a basic, fully functional app within an hour or less. App Inventor runs as a web service administered by staff at MIT's Center for Mobile Learning - a collaboration of MIT's Computer Science and Artificial Intelligence Laboratory (CSAIL) and the MIT Media Lab. 
The Android App is designed using MIT App Inventor by linking different blocks. The design procedure is explained as under Fig. 14

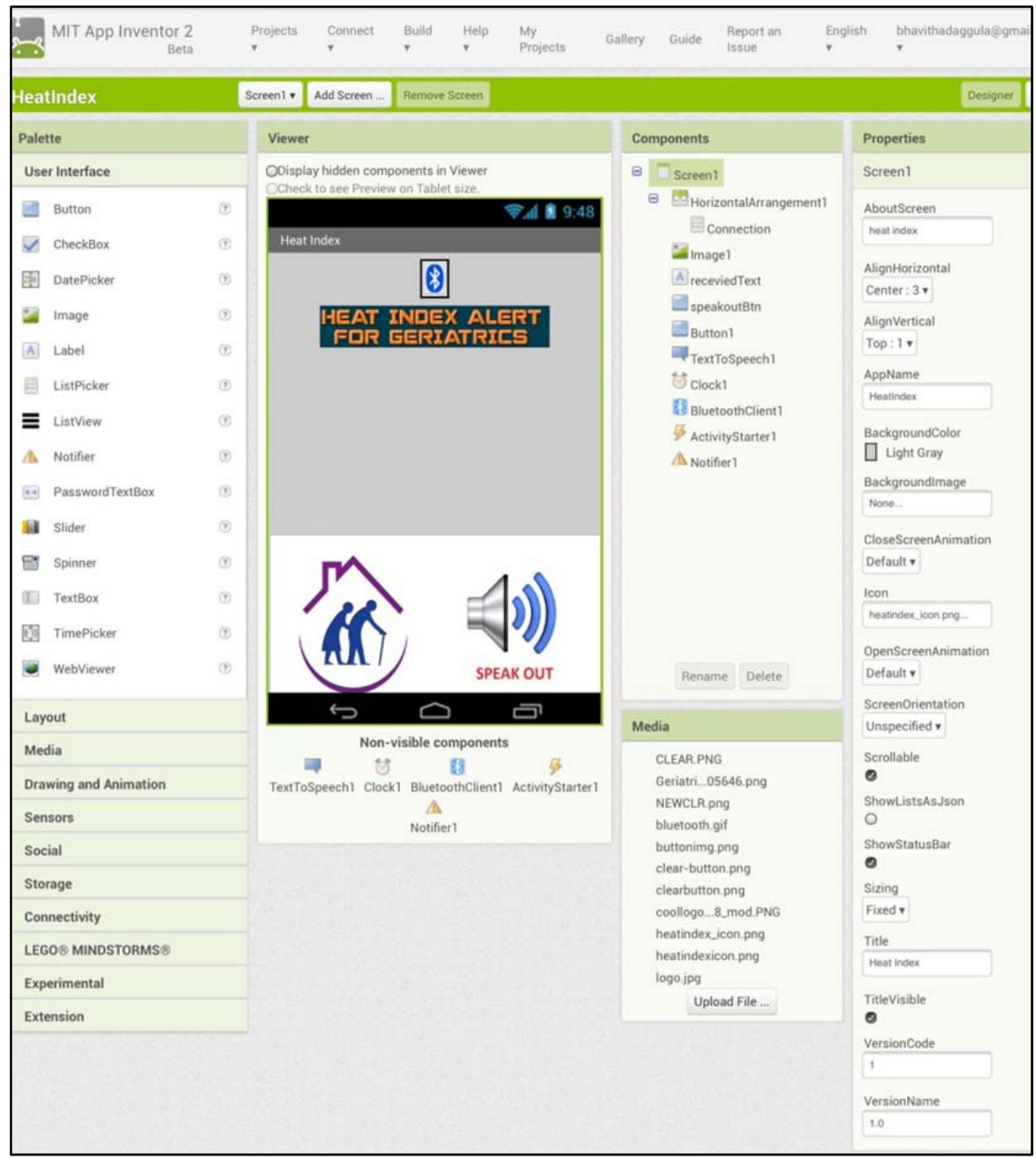

Fig.14. Screenshot of MIT APP INVENTOR

Fig.15 refers to initialization of screen1(App Screen) and connection status of BluetoothClient1.

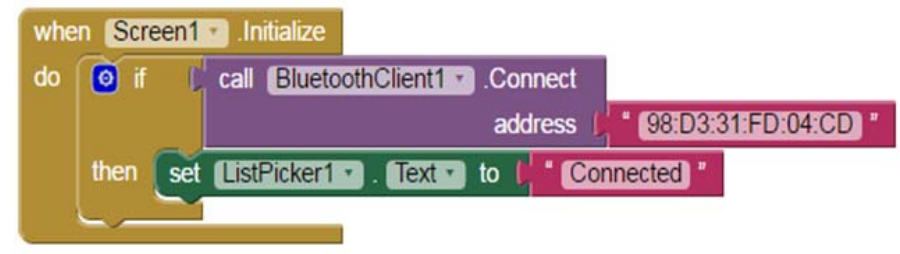

Fig.15. Bluetooth Connection

Using the block shown in Fig 16, Bluetooth client is selected based on the MAC addresses listed.

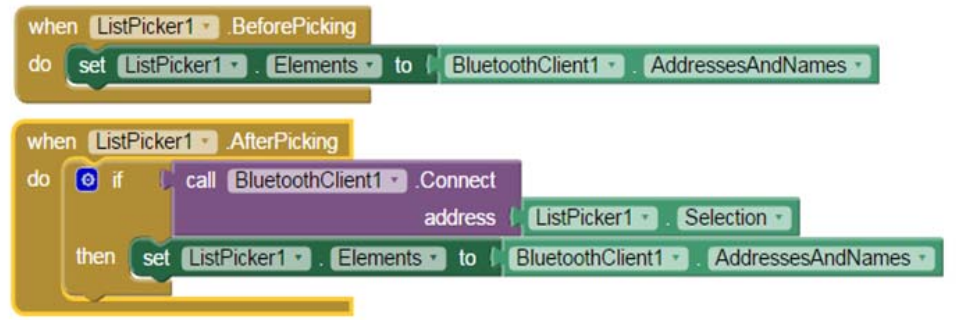

Fig.16 Elements List Picking 
The block referred in Fig17, is used to create global variables. It takes any type of value as an argument. Global variables are used in all procedures or events so this block stands alone.

\section{initialize global (bytesRead) to " "O"}

Fig.17 Global Initialization

Retrieving the variable values into the app for a period is referred by the block in Fig 18 .

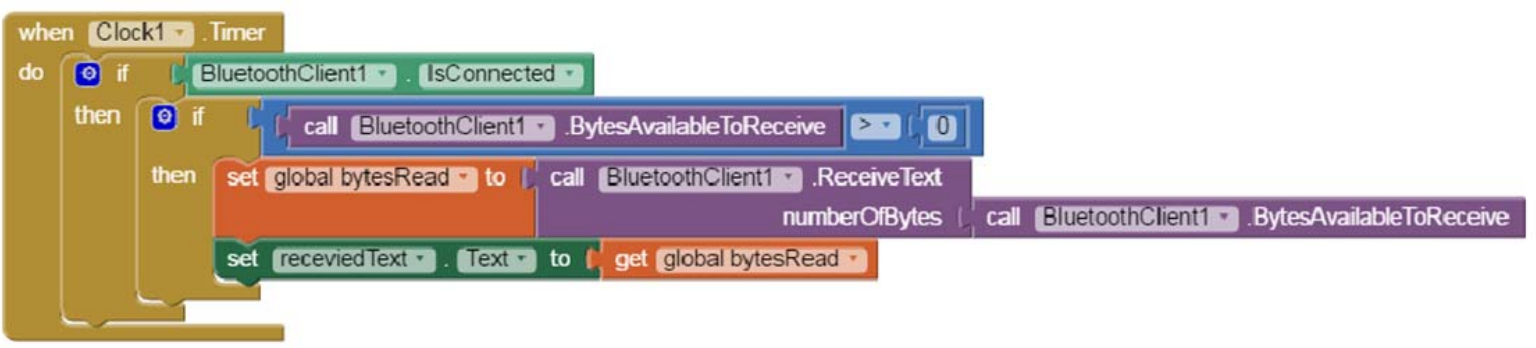

Fig.18. Clock Timer

The block referred in Fig 19, shows the button used for reading out the displayed values in the label. An option is provided to read out the values by clicking a button.

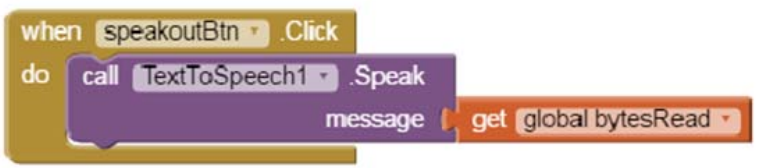

Fig.19. Speak out buttons

Button 1 is used to clear the data, So that the new data is received \& displayed in the label. The block structure for this operation is shown in Fig 20.

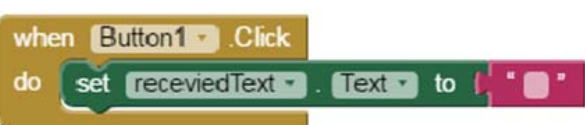

Fig.20 Clear Button

\section{FinAL ANDROID APPLICATION SCREEN}

The screenshot of the Application in android mobile phone developed using MIT APP INVENTOR is shown in Fig.22 and Fig.21 shows the application icon.

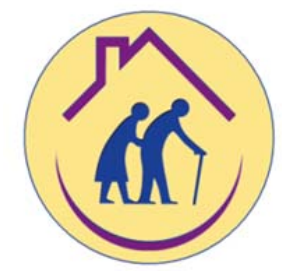

Fig.21. Application icon 


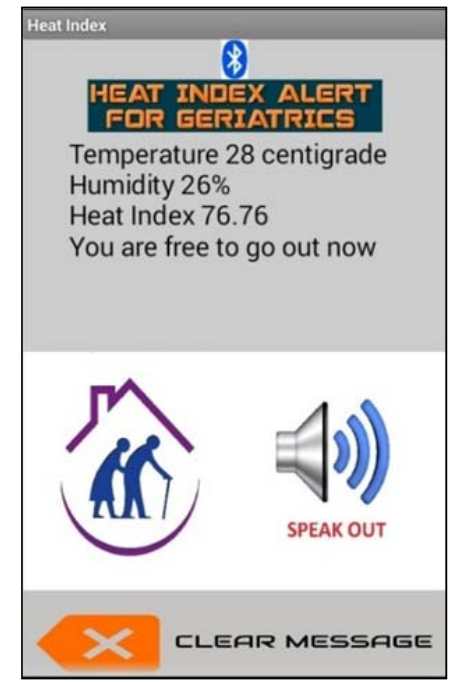

Fig.22 Final Android APP output screen

The final design of the device Heat Index Medical Alert System for Geriatrics is shown in the Fig.23.

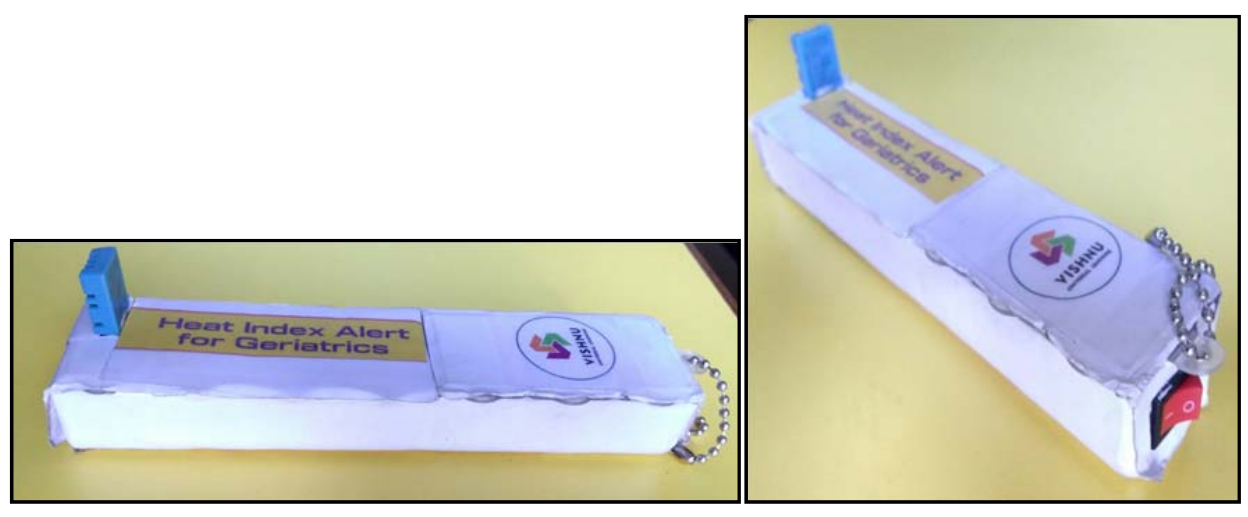

Fig.23. Heat Index Alert Device

\section{CONCLUSION}

The proposed Android based medical alert system is placed outside the house and tested under different atmospheric conditions and is observed very useful not only for geriatrics but also for the patients under medication. But in colder countries during winter, geriatrics experience the problems like increase in systolic blood pressure, respiratory diseases including flu, etc.

In order to make this device suitable for colder countries there is a need for replacing DHT11 sensor. As the measurable range of DHT11 sensor is limited to $0 \mathrm{oC}$ to $50 \mathrm{oC}$ which is not suitable for colder countries, it can be replaced with DHT22 whose range of temperature measurement is $-40 \mathrm{oC}$ to $80 \mathrm{oC}$ and increased range of relative humidity with 0 to $100 \%$. DHT22 is also advantageous than DHT11 with accuracy in temperature of $+0.5 \mathrm{oC}$ and relative humidity of $+2 \%$.

Along with DHT22 this project can be extended by including different sensors using which we can provide the access for healthy living.

\section{REFERENCES}

[1] Parsons, K. (2003). Human Thermal Environments: The effects of hot, moderate, and cold environments on human health, comfort and performance (2nd ed.). New York: Taylor \& Francis Inc.

[2] Zanobetti, A., O'Neill, M. S., Gronlund, C. J., \& Schwartz, J. D. (2012). Summer temperature variability and long-term survival among elderly people with chronic disease. Proceedings of the Natural Academy of Sciences, 109(17): 6608 - 6613.

[3] Braga AL, Zanobetti A, Schwartz J. The effect of weather on respiratory and cardiovascular deaths in 12 U.S. cities. Environ Health Perspect. 2002;110:859-863.

[4] Hajat S, Armstrong BG, Gouveia N, Wilkinson P. Mortality displacement of heat-related deaths: A comparison of Delhi, São Paulo, and London. Epidemiology. 2005;16:613-620. 
[5] Braga AL, Zanobetti A, Schwartz J. The time course of weather-related deaths. Epidemiology. 2001;12:662-667.

[6] Medina-Ramón M, Schwartz J. Temperature, temperature extremes, and mortality: A study of acclimatization and effect modification in 50 United States cities. Occup Environ Med. 2007;64:827-833

[7] NOAA. (2009). Heat Index Chart. NOAA National Weather Service: Peachtree, GA Office, http://srh.noaa.gov/ffc/?n=hichart. Retrieved from Heat Index: http://srh.noaa.gov/ffc/?n=hichar

[8] NOAA. (2013). National Weather Service Heat Index. Heat Index. National Oceanic and Atmospheric Administration. http://www.wrh.noaa.gov/psr/general/safety/heat/heatindex.png

[9] NOAA. (2013). National Weather Service Heat Index. Heat Index. National Oceanic Atmospheric Association: http://www.nws.noaa.gov/os/heat/images/heatindex.png

[10] NOAA. (2014). Heat: A Major Killer. Retrieved from NOAA's National Weather Service: Office of Climate, Water, and Weather Services: http://www.nws.noaa.gov/os/heat/index.shtml\#heatindex

[11] NOAA's (2015) National Weather Service: Common heat related illness:http://www.nws.noaa.gov/om/heat/heat-illness.shtml

[12] Sparkfun Electronics (US) : https://www.sparkfun.com/products/11113

[13] Sparkfun Electronics (US) : https://www.sparkfun.com/products/9716

[14] Sparkfun Electronics (US) : https://learn.sparkfun.com/tutorials/using-the-arduino-pro-mini-33v

[15] Adafruit Industries : https://www.adafruit.com/product $/ 386$

[16] https://wiki.eprolabs.com/index.php?title=Bluetooth_Module_HC-05

\section{AUTHOR PROFILE}

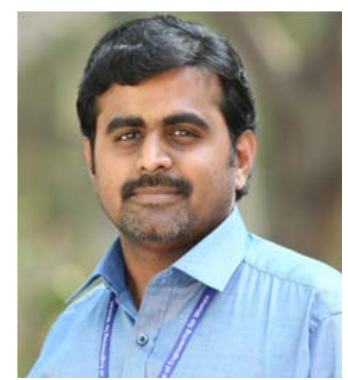

R.Priyakanth received B.Tech degree in Electronics \& Control Engineering from PVP Siddhartha Institute of Technology, Vijayawada, A.P, India and M.Tech degree in Communication and Radar Systems from K L University, Vaddeswaram, Guntur Dist., A.P, India in 2002 and 2005 respectively. Having 13 years of experience in teaching and 1 year in industry, currently he is working as Asst. Professor in the department of Electronics and Communication Engineering, BVRIT Hyderabad College of Engineering for Women, Hyderabad, Telangana, India. He is pursuing his research under JNTUK, Kakinada in Multimodal Signal Processing. His other research interests include Bio-Medical Imaging and IOT.

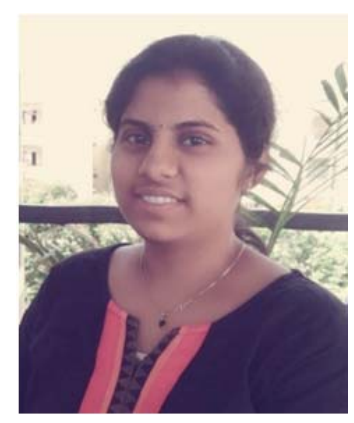

Daggula Bhavitha is a Final year student in the Department of Electronics and Communication Engineering, BVRIT Hyderabad College of Engineering for Women, Hyderabad, Telangana, India. Her interests include IOT. She is placed in CDK Global, Hyderabad as Installation Developer.

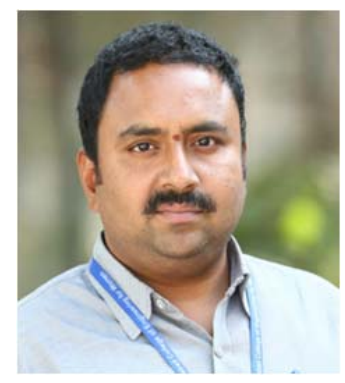

Mahesh Babu Katta received B.Tech degree in Electronics \& Communication Engineering from SRKR Engineering College Bhimavaram, A.P, India and M.Tech degree in Electronics and Communication Engineering from JNTUH, Hyderabad, Telangana, India in 2003 and 2012 respectively. Having 14 years of teaching experience currently he is working as Asst. Professor in the department of Electronics and Communication Engineering, BVRIT Hyderabad College of Engineering for Women, Hyderabad, Telangana, India. His research interests include GPS and IOT.

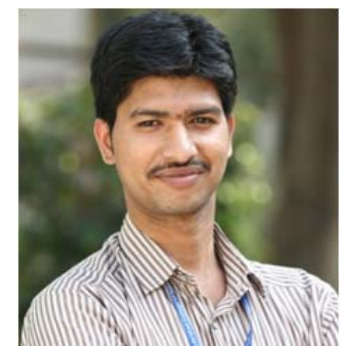

N. M. Sai Krishna received B. Tech degree in Electronics \& Communication Engineering from, Anna University, Chennai, T.N, India and M. Tech degree from JNTU Kakinada, A.P, India in 2008 and 2012 respectively. Having 7 years of teaching experience he is working as Assistant Professor in the department of Electronics and Communication Engineering in BVRIT Hyderabad College of Engineering for Women, Hyderabad, Telangana, India. His areas of interest are IOT and VLSI and Applications. 